UNIVERSIDADE DE SÃO PAULO

INSTITUTO DE GEOCIÊNCIAS

\title{
ASPECTOS GEOLÓGICOS E MINERALÓGICOS DA MINA DE DIAMANTES DE ROMARIA, MINAS GERAIS
}

Fernando de Mattos Coelho

Orientador: Prof. Dr. Darcy Pedro Svizzero

\section{DISSERTAÇÃO DE MESTRADO}

Programa de Pós-Graduação em Mineralogia e Petrologia 


\section{RESUMO}

A Mina de diamantes de Romaria está localizada no perímetro urbano da cidade de Romaria, na região oeste de Minas Gerais. Durante os trabalhos de mineração executados nos últimos cem anos, foi lavrada uma área de aproximadamente $1 \mathrm{~km}^{2}$ de sedimentos. $\mathrm{O}$ local está situado na borda NE da Bacia do Paraná, na margem direita do Rio Bagagem, entre os Ribeirões Água Suja e Marrecos.

Neste local vem sendo lavrado um conglomerado polimítico da Formação Uberaba, Grupo Bauru, pertencente ao Cretáceo Superior. Ele é constituído por clastos de micaxistos, anfibolitos, filitos e veios pegmatóides do Pré-Cambriano; arenitos da Formação Botucatu e basaltos da Formação Serra Geral. Possui matriz areno-argilosa onde foram identificadas as fases caulinita, illita e quartzo por difratometria. Sua espessura na área da mina oscila em torno de $6 \mathrm{~m}$.

Os minerais pesados separados do conglomerado diamantífero amostrado nas Frentes de Lavra 2 (Ferraria), 6 (Mangueiras) e na Cata exploratória do Sarkis, situada fora da área minerada, são constituídos em sua maior parte por fases opacas, entre as quais se destaca a magnetita, representando $50 \%$ em volume do concentrado. Outras fases opacas incluem hematita, ilmenita e fragmentos de lateritos. Entre as fases transparentes, destacase a granada que ocorre nas cores vermelha clara, vermelha escura, roxa, violeta e laranja, além de outros minerais derivados de rochas do embasamento cristalino. Análises químicas realizadas pela microssonda eletrônica revelaram que a ilmenita contém teores de $\operatorname{MgO}(7,4$ - 11,4 \% em peso) e de $\mathrm{Cr}_{2} \mathrm{O}_{3}(0,0-2,9 \%$ em peso) típicos de rochas kimberlíticas. Da mesma forma, as granadas correspondem a piropos ricos em $\mathrm{Cr}_{2} \mathrm{O}_{3}(0,2-6,7 \%$ em peso) correspondendo aos grupos G9 (Iherzolitos), G5 e G4 (piroxenitos) e G10 (harzburgitos), sendo semelhantes a granadas das principais províncias kimberlíticas conhecidas. 0 diamante, por sua vez, contém microestruturas típicas semelhantes a diamantes de outras localidades. Foram identificadas trígonos em faces octaédricas, bem como microestruturas de simetria senária semelhantes às observadas em diamantes do lamproíto Argyle, na Austrália. Foram descritas microestruturas quadráticas nos cristais cúbicos, e degraus resultantes da dissolução de planos de crescimento cristalino em superfícies curvas de cristais rombododecaédricos.

Atualmente a mina está paralisada desde 1984 devido a uma dívida contraída pela Extratífera de Diamantes do Brasil (EXDIBRA) com o Banco Nacional de Desenvolvimento Social. Apesar do potencial mineral existente no local, qualquer tentava de lavra só poderá ser executada mediante a quitação desta dívida. 


\begin{abstract}
The diamond Mine of Romaria is located in the northeast border of the Paraná Sedimentary Basin, nearby the town of Romaria, in western Minas Gerais State, Brazil. The mining place is situated on the right side of the Bagagem River, comprising an area of $1 \mathrm{~km}^{2}$ between the Água Suja and Marrecos streams.

At this place diamonds have been washed from a Cretaceous polimictic conglomerate of the Uberaba Formation, Bauru Group, since the end of the nineteen century. This heterogeneous diamond-bearing conglomerate contains large conglomerate blocks of several lithologies with dimensions up to $0.80 \mathrm{~m}$, set in an arenous-clayish matrix where kaolinite, illite and quartz have identified among the clasts such as mica and staurolite schists, phyllites and amphibolites of the Araxá Group, quartzites of the Canastra Group, arenites of the Botucatu Formation and basalts of the Serra Geral Formation.
\end{abstract}

The concentrates obtained by washing the conglomerate contains large amounts of opaques phases mainly magnetite which may reach up to $50 \%$ in volume. Other opaques are represented by hematite, ilmenite, rutile, limonite as well as rock fragments of mica schists and complex intergrowths of laterites. The mineralogical assemblages of the transparent phases include staurolite, amphibole, epidote, kyanite, monazite, tourmaline, zircon and diamond as well.

Electron micro probe analyses revealed that the ilmenites contain MgO (7.4-11.4 wt\%) and $\mathrm{Cr}_{2} \mathrm{O}_{3}$ (0.0-2.9 wt\%) contents similar to their counterparts of kimberlites from worldwide localities. Moreover, garnets are chromium rich pyropes with $\mathrm{Cr}_{2} \mathrm{O}_{3}$ ranging from 0.2 up to 6.7 wt \%. The use discriminating diagrams revealed that most of the analysed sampled plot in the fields G9 and G3-G5 corresponding to Iherzolitic and pyroxenitic parageneses, respectively. The plots include some rare G10 (harzbugitic) and G0 (unclassified) samples corresponding to garnets derived from rocks of the crystalline basement. Although diamonds have not been mined in the last years a small parcel produced by local diggers (garimpeiros) was available for physical studies including color and crystalline morphology. Several microstructures have been observed in octahedral crystal such as trigons and a pseudo-hexagonal microstructure observed in diamonds from lamproites. Cubic crystals showing the combination of the cube and dodecahedral revealed microstructures of square symmetry. Concerning dodecahedral crystal hillocks produced by dissolution were observed on the rounded faces of the samples.

Presently the Mine of Romaria is closed since 1984 due to an old debt contracted by late owner Extratífera de Diamantes do Brasil (EXDIBRA) with the Brazilian Federal Agency of the Banco Nacional de Desenvolvimento Social (BNDES). 
ÍNDICE

RESUMO

ABSTRACT

$\begin{array}{ll}\text { 1. INTRODUÇÃO } & 001\end{array}$

$\begin{array}{ll}1.1 \text { - Objetivos e organização do trabalho } & 004\end{array}$

$\begin{array}{ll}1.2 \text { - Localização da área } & 004\end{array}$

$\begin{array}{ll}1.3 \text { - Aspectos fisiográficos } & 005\end{array}$

2. MATERIAIS, MÉTODOS E AMOSTRAGEM 009

$\begin{array}{ll}2.1 \text { - Trabalhos de campo } & 009\end{array}$

$\begin{array}{ll}2.2 \text { - Trabalhos de laboratório } & 013\end{array}$

2.2.1 - Microscopia óptica 013

2.2.2 - Difração de raios X 013

$\begin{array}{ll}2.2 .3 \text { - Microssonda eletrônica } & 014\end{array}$

2.2.4 - Microscopia eletrônica de varredura (MEV) 015

3. CONTEXTO GEOLÓGICO REGIONAL 018

$\begin{array}{ll}3.1 \text { - Cráton do São Francisco } & 018\end{array}$

$\begin{array}{ll}3.2 \text { - Faixa Brasília } & 019\end{array}$

3.2.1 - Faixa Brasília Setentrional 021

3.2.1.1 - Grupo Paranoá $\quad 021$

$\begin{array}{ll}\text { 3.2.2 - Faixa Brasília Meridional } & 021\end{array}$

3.2.2.1 - Grupo Bambuí 022

3.2.2.2 - Grupo Vazante 023

$\begin{array}{ll}\text { 3.2.2.3 - Grupo Canastra } & 024\end{array}$

3.2.2.4 - Grupo Araxá 024

3.2.2.5 - Grupo Ibiá 025

$\begin{array}{ll}3.3 \text { - Bacia do Paraná } & 026\end{array}$ 
3.3.1 - Grupo São Bento

3.3.2 - Grupo Bauru

027

3.4 - Bacia SanFranciscana

3.4.1 - Grupo Areado

029

3.4.2 - Grupo Mata da Corda

029

3.4.3 - Província Ígnea do Alto Paranaíba

029

3.4.4 - Coberturas Lateríticas

030

4. A MINA DE ROMARIA

033

4.1 - Geologia da Mina de Romaria

037

4.1.1 - Grupo Araxá

036

4.1.2 - Grupo São Bento

045

4.1.3 - Grupo Bauru

047

4.1.3.1 - Formação Marília

5. MINERAIS PESADOS

5.1 - Granada

060

5.2 - Ilmenita

072

5.3 - Diamante

081

6. CONCLUSÕES

7. REFERÊNCIAS BIBLIOGRÁFICAS

8. AGRADECIMENTOS 


\section{ÍNDICE DAS FIGURAS}

FIGURA 01 - Localização geográfica da cidade

de Romaria e áreas adjacentes.

FIGURA 02 - Detalhe da região adjacente à Mina

de diamante de Romaria.

FIGURA 03 - Mapa das principais unidades tectônicas

regionais na área da Mina de Romaria.

FIGURA 04 - $\quad$ Mapa geológico da região da Mina de

Romaria.

FIGURA 05 - Delimitação da área correspondente ao

Manifesto de Lavra da Extratífera de Diamantes

do Brasil (EXDIBRA).

FIGURA 06 - Planta das Frentes de Lavra operadas pela

EXDIBRA.

FIGURA $07 \quad$ - $\quad$ Mapa geológico local da Mina de Romaria

destacando-se as oito Frentes de Lavra mineradas

pela EXDIBRA.

FIGURA 08 - Difratograma dos clastos de argila branca

presente no conglomerado diamantífero

da Mina de Romaria.

FIGURA 09 - Difratograma da argila de coloração rosa

presente na matriz do conglomerado

da Mina de Romaria.

050

FIGURA 10 - Diagrama $\mathrm{Mg} /(\mathrm{Mg}+\mathrm{Fe}) \times \mathrm{Ca} /(\mathrm{Ca}+\mathrm{Mg})$ de SCHULZE

(2003), ressaltando os trendes mantélicos das granadas

da Mina de Romaria.

FIGURA 11 - Diagrama $\mathrm{Mg} /(\mathrm{Mg}+\mathrm{Fe}) \times \mathrm{Cr}_{2} \mathrm{O}_{3}$ de SCHULZE (2003),

ressaltando os trendes peridotítico e eclogítico

das granadas da Mina de Romaria. 


\begin{tabular}{|c|c|c|c|}
\hline \multirow[t]{3}{*}{ FIGURA 12} & \multirow[t]{3}{*}{-} & Diagrama $\mathrm{CaO} \times \mathrm{Cr}_{2} \mathrm{O}_{3}$ ilustrando as variações & \\
\hline & & composicionais de granadas da Mina de Romaria, & \\
\hline & & utilizando o diagram de GRUTTER et al. (2004). & 074 \\
\hline \multirow[t]{3}{*}{ FIGURA 13} & \multirow[t]{3}{*}{-} & Variação dos teores de $\mathrm{MgO} \times \mathrm{TiO}_{2}$ de ilmenitas & \\
\hline & & da região da Mina de Romaria, utilizando o & \\
\hline & & diagrama de WYATT et al. (2004). & 080 \\
\hline \multirow[t]{3}{*}{ FIGURA 14} & \multirow[t]{3}{*}{-} & Comparação entre as ilmenitas da Mina de Romaria & \\
\hline & & com ilmenitas de outros locais, utilizando o diagrama & \\
\hline & & $\mathrm{MgO} \times \mathrm{Cr}_{2} \mathrm{O}_{3}$ de WYATT et al. (2004). & 080 \\
\hline \multirow[t]{3}{*}{ FIGURA 15} & \multirow[t]{3}{*}{-} & Esquema ilustrativo de KHOKHRYAKOV, A.F. \& & \\
\hline & & PAL'YANOV, Y.N. (2007) da evolução cristalográfica de & \\
\hline & & diamantes naturais sob a ação de dissolução. & 083 \\
\hline FIGURA 16 & - & Aspectos cristalográficos de cristais octaédricos. & 086 \\
\hline FIGURA 17 & - & Aspectos cristalográficos de cristais cúbicos. & 089 \\
\hline \multirow[t]{2}{*}{ FIGURA 18} & \multirow[t]{2}{*}{-} & Aspectos cristalográficos de cristais & \\
\hline & & Rombododecaédricos. & 090 \\
\hline
\end{tabular}




\section{ÍNDICE DE TABELAS}

TABELA 01 - Principais parâmetros de comparação entre os

conglomerados diamantíferos das Formações

Sopa Brumadinho (Mesoproterozóico) e Uberaba

(Cretáceo Superior).

TABELA 02 - $\quad$ Análises químicas de granadas de coloração

vermelha clara da Frente de Lavra 6.

TABELA 03 - $\quad$ Análises químicas de granadas de coloração

vermelha escura da Frente de Lavra 6.

TABELA 04 - $\quad$ Análises químicas de granadas de coloração

roxa da Frente de Lavra $6 . \quad 068$

TABELA 05 - $\quad$ Análises químicas dos macrocristais de granada

da Cata exploratória do Sarkis. 069

TABELA 06 - $\quad$ Análises químicas de granadas de coloração

laranja da Frente de Lavra $6 . \quad 070$

TABELA $07 \quad$ - $\quad$ Análises químicas de granadas violetas da

Cata exploratória do Sarkis. 071

TABELA 08 - $\quad$ Análises químicas de ilmenitas da Frente de

$\begin{array}{ll}\text { Lavra } 2 . & 078\end{array}$

TABELA 09 - $\quad$ Análises químicas de ilmenitas da Cata

exploratória do Sarkis. 079

TABELA 10 - $\quad$ Características físicas do diamante da Mina

de Romaria. 


\section{INDICE DAS FOTOGRAFIAS}

FOTOGRAFIA 01 Vista da cidade de Romaria tomada a partir do interior da Mina de Romaria.

FOTOGRAFIA 02 Vista do saco de 20 litros utilizado na

amostragem do conglomerado diamantífero.

FOTOGRAFIA 03 Betoneira utilizada na pré-deslamagem

das amostras do conglomerado diamantífero.

FOTOGRAFIA 04 Lavagem e separação dos constituintes do

conglomerado utilizando peneiras e batéia.

FOTOGRAFIA 05 Concentrado final obtido durante a fase de

amostragem do conglomerado diamantífero.

FOTOGRAFIA 06 Paleocanais do embasamento no micaxisto Araxá

Na Frente de Lavra 1.

FOTOGRAFIA 07 Dique de anfibolito, encaixado no micaxisto

Araxá, presente na Frente de Lavra 6.

FOTOGRAFIA 08 Vista da pedreira de arenito Botucatu na Frente de Lavra 7.

FOTOGRAFIA 09 Vista dos constituintes do conglomerado na Frente de Lavra 8 (Edson Pires).

FOTOGRAFIA 10 Bloco de basalto amigdaloidal na na Frente de Lavra 8 (Edson Pires).

FOTOGRAFIA 11 Falha em arenito Botucatu exposto na Frente de Lavra 2.

FOTOGRAFIA 12 Granadas de cores variadas da Frente de Lavra 6.

FOTOGRAFIA 13 Granadas de coloração laranja e vermelha escura da Frente de Lavra 6.

FOTOGRAFIA 14 Cristais de ilmenita da cata do Sarkis cobertos por película de leucoxênio. 